10. Herr Král: „Mittheilungen über Hautmikrophyten und erläuternde Bemerkungen zu seiner bacteriologischen Ausstellung."

Anfangs vorigen Jahres begann ich an der dermatologischen Klinik des Herrn Prof Pick mit bacteriologischen Untersuchungen, welche die Bearbeitung einer Flora der pathologisch veränderten Haut des Menschen zum Zwecke hatten.

Die subtile Anwendung der Koch'schen Trennungsmethoden, das Herbeiziehen einiger aus technischen Gründen selten benützter Nährböden und die peinliche Beobachtung constanter Zeit-, Raum- und Temperaturgrössen bei vergleichenden Versuchsreihen liessen zahlreiche Resultate erzielen, deren umfassende Publicirung einem späteren Zeitraume vorbehalten werden muss.

Ich beschränke meine vorläufige Mittheilung blos auf die culturellen Ergebnisse aus Favus und Eczema marginatum, welche dadurch einiges Interesse gewinnen, dass bei einer so geringen Anzahl untersuchter Fälle und zwar bei den zwei Favusfällen nicht weniger als sechs, bei den zwei Eczema marginatum-Fällen drei Fadenpilze reingezüchtet wurden, welche die gemeinsame Eigenschaft besitzen, bei Körpertemperatur rasch und üppig, bei Zimmertemperatur langsam und meist auch mangelhaft zu gedeihen.

Als Nährsubstrate wurden benützt: Peptonisirte Fleischbrühe, zehnprocentige Nährgelatine, zweiprocentiger Nähragar, Kartoffelscheiben, Reisscheiben, Rübenschnitte, Fleischscheiben und Weizenbrod. Es wurden von den erbaltenen Pilzen auf allen diesen Nährböden, mit Ausnahme von Bouillon und Nährgelatine, Dauerpräparate angefertigt, welche ich mir hier vorzulegen erlaube.

Das hervorragendste Hilfsmittel für die makroskopische und mikroskopische Differentialdiagnose der bei Körpertemperatur gedeihenden Fadenpilze sind die sogenannten Dauerplatten, welche hier nur als Agarplatten Verwendung finden können. Man säet mit einer fein zugespitzten Platinnadel, deren Ende rechtwinkelig umgebogen wird, einige Sporen möglichst in der Mitte der noch flüssigen, auf 42 bis $45^{\circ}$ C. abgekühlten Platte aus, und kann nun von dem Momente des Erstarrens an alle Vegetationsphasen 
ununterbrochen beobachten. Für die makroskopische Entwickelung sind die günstigsten Bedingungen dadurch gegeben, dass jede das Wachsthum behindernde Raumconcurrenz ausgeschlossen bleibt. Man erhält Rasen von mitunter geradezu colossalen Dimensionen, welche constante und prägnante Unterscheidungsmerkmale auch für jene Pilze nachweisen lassen, welche sich auf anderen Nährböden makroskopisch schwierig oder gar nicht differenziren.

Indem ich mich vorzugsweise auf die Demonstration der Agardaiuerplatten der rein gezüchteten Pilze beschränke, lege ich zur Constatirung der Constanz der durch diese Methode erzielten Vegetationsbilder stets mehrere Präparate des gleichen Pilzes vor. In einer Tabelle, welche diesen Mittheilungen beigegeben werden wird, ist das Verhalten der Pilze den anderen Nährmedien gegenüber eingehender geschildert.

Der erste Favusfall betraf ein fünfundzwanzigjähriges Mädchen mit intensivem Kopffavus, deren Haarwurzeln vor Beginn der therapeutischen Eingriffe und nach drei Monaten gelegentlich einer eingetretenen Recidive neuerdings zur Untersuchung gelangten.

Bei der ersten Untersuchung wurde ausschliesslich der Fadenpilz 1

erhalten, welcher auf Agardauerplatten Rasen bildet, deren periphere moos- oder schneekrystallartigen, weithin in den Agar sich erstreckenden Emissionen ihn scharf von den übrigen fünf bei Favus gefundenen Pilzen trennen. Er charakterisirt sich ferner dadurch, dass er auf Gelatine am langsamsten von allen wächst, auf Reisscheiben und Weizenbrod nur luftmycellose Rasen bildet, und dass seine Bouillonculturen von äbulichen moosartigen Bildungen begrenzt werden, wie sie in auffälligerer Weise in den Agarplatten vorkommen.

Bei der zweiten, drei Monate später erfolgten Untersuchung von Favushaaren desselben Individuums wurde der

Fadenpilz 2

erhalten.

In Agarplatten beginnt die Schwellnng der ausgesäeten 
Sporen nach wenigen Stunden. In $15 \mathrm{~h}$. hat jede der Sporen einen Keimschlauch getrieben, der Rasen erreicht in $14 \mathrm{~d}$. einen Durchmesser von $40-50 \mathrm{Mm}$. und ist mit kurzen weissen Lufthyphen bedeckt, welche ihm das bekannte mehlbestaubte Aussehen verleihen. Der Pilz wächst auf Agar am raschesten und verfärbt ibn 'nächst dem Pilze 5 am intensivsten. Auch die Unterfläche des Rasens ist dunkler verfärbt, als bei den übrigen Pilzen.

Das Untersuchungsmateriale des zweiten Favusfalles entstammte einem dreizehnjährigen Schulknaben.

Aus den der Basis eines jüngeren Scutulums entnommenen Schüppchen wurde der

\section{Fadenpilz 3}

reingezüchtet, welcher sich auf den verschiedenen Nährböden dem Pilze 2 ähnlich verhält.

Auf der Agardauerplatte erreicht der Rasen dieses Pilzes wohl auch nahezu dieselbe Grösse wie Pilz 2, keimt aber später aus und seine Vegetationsfortschritte sind namhaft verzögertere. Die Unterfläche des Rasens ist im Gegensatze zu 2 blos strohgelb verfärbt. Gelatine verflüssigt er bedentend rascher und verfärbt sie weit intensiver als 2.

Aus den gleichzeitig mit den Scutulumschüppchen ausgesäeten Haarpartikelchen wurden die beiden Pilze 4 und 5 erhalten.

Auch der

\section{Fadenpilz 4}

keimt bald nach seiner Aussaat in Agardauerplatten. In $15 \mathrm{~h}$. sind einige der Sporen derart angeschwollen, dass ihr Durchmesser das drei- bis vierfache des ursprünglichen beträgt. Fernerhin wächst er aber langsamer als die Pilze 2 und 3, etwa gleichen Schritt haltend mit den Pilzen 1 und 5. Seine Rasen erreichen erst in $24 \mathrm{~d}$. einen Durchmesser von $30 \mathrm{Mm}$. Deren Unterfläche ist strohgelb gefärbt. Bei 20-30 d. alten Agardauerplattenculturen erscheint die Randhyphenzone wie mit "weissen Körnchen " bestreut, welche Salzefflorescenzen ähnlich sehen. Bei $40--50$ d. alten Bouillonculturen kann eine ähnliche Errscheinung wahrgenommen werden. Sie entspricht den moosartigen Emissionen des Pilzes 1, auf welche wir noch zurückkommen werden. 
Nährgelatine wird erst nach Ablauf von 14 d. im unmittelbaren Umkreise des Rasens erweicht und späterhin verflüssigt, während bei den anderen 5 Pilzen der Beginn der Erweichung bezw. Verflüssigung meist bereits nach den ersten $24 \mathrm{~h}$. eingetreten ist.

Der Fadenpilz 5

keimt rasch aus, bringt es aber auf den Agarplatten nur zu Rasen von circa $20 \mathrm{Mm}$. Durchmesser. Was ihn vor den übrigen besonders auszeichnet, sind die charakteristischen büschelförmigen Protuberanzen an der Rasenperipherie, deren Entstehung wieder dem Entwickelungsgange der moosartigen Emissionen des Pilzes 1 "und dem der "woissen Körnchen" des Pilzes 4 analog ist. Der Pilz wächst auf Gelatine üppiger als die anderen, verflüssigt sie am energischesten und verfärbt sie am intensirsten.

Nach drei Monaten wurden aus der Unterfläche eines Scutulums desselben Individuums neuerdings Plattenculturen angelegt und aus selben der

rein gewonnen.

\section{Fadenpilz 6}

In Agardaperplatten findet man die Sporen nach 48 h. kaum geschwellt, der Rasen erreicht erst in $13 \mathrm{~d}$, einen Durchmesser von $20 \mathrm{Mm}$., worauf die Vegetation sistirt. Er wächst am langsamsten, die Verfärbung der Unterfläche und des Agars ist so intensiv wie bei 2. Die periphere Hyphenzone ist verhältnissmässig sehr schmal und tendirt ebenfalls zur Bildung von Protuberanzen, welche jedoch mehr vereinzelt und weit kleiner auftreten, als bei dem Pilze 5.

Auf Gelatine beginnt das Wachsthum erst am achten Tage makroskopisch sichtbar zu werden, obzwar die Verflüssigung sich bereits am 4. d. durch Einsinken der Impfspur manifestirt. Der Verflüssigungsgrad entspricht jenem des Achorion.

Das Vegetationsbild auf Kartoffelscheiben lässt ihn leicht und scharf von den Kartoffelculturen der vorangegangenen Pilze unterscheiden. Er besitzt nämlich, gleich dem Pilze 1 und im Gegensatze zu den anderen, keinen peripheren flachen Rasen um den prominirenden centralen Theil der Cultur herum, sondern seine zierlichen Falten und Wülstchen steigen scharf abgesetzt und senkrecht aus dem Substrat hervor. Von dem Pilze 1 trennt ihn 
aber entschieden Farbe, Form und das kümmerliche Wachsthum des ersteren.

Die moosartigen Emissionen des Pilzes 1, die "weissen Körnchen" des Pilzes 4 und die büschelförmigen Protuberanzen des Pilzes 5 verdanken ihre Entstehung dem Auskeimen einzelner an den Randhyphen gebildeter Dauerformen, welche unter günstigen Verhältnissen eine neue Generation etabliren, von welcher aus sich der Vorgang wiederholen kann, so lange noch vegetationsfreies, nicht erschöpftes Substrat und höhere Temperatur zur Verfügung stehen. Der Vorgang lässt sich an den peripheren Fruchthyphen des Pilzes 4, ihrer aussergewöhnlichen Länge halber, deutlich in allen Phasen verfolgen. Eine der zahlreichen seitenständigen Sporen schwillt beträchtlich an, treibt einen kurzen dicken Keimschlauch, welcher rasch zur viel verästelten Hyphe und schliesslich zu einem später auch makroskopisch wahrnehmbaren Mycel auswächst, welches als "weisses Körnchen" bezeichnet wurde. Von diesem Mycel werden wieder lange Fruchthyphen in das noch vegetationsfreie Substrat ausgesendet, an welchen sich der geschilderte Vorgang von Neuem abwickelt.

Betrachten und vergleichen wir nun auch die sechs Pilze bei schwacher Vergrösserung mit einander und mit Achorion. Bei den Dauerplatten bleibt die mikroskopische Untersuchung allerdings nur auf die peripheren Partien des Rasens beschränkt. Dagegen gewähren sie uns den unschätzbaren Vortheil, dass wir das Wachsthum der Cultur jederzeit in dem uns am passendsten erscheinenden Momente durch Entfernung ans dem Brütofen sistiren oder doch wesentlich verzögern und die Cultur in dem gewünschten Entwickelungsstadium lebend conserviren können.

Die Pilze 2 und 3 haben untereinander und mit Achoriou die meiste Aehnlichkeit. An keinem von ihnen treten an den Randhyphen kolbige Anschwellungen oder Knöpfehen auf. Doch hat 2 viel zartere und kürzere Randhyphen mit längeren und weniger zahlreichen Seitenästen aufzuweisen als 3. Dieser wieder besitzt eine so reiche oft knospenartige Verästelung seiner sehr langen, geradlinig verlaufenden Randhyphen, dass er sich von 2 und den in grossen Schlangenwindungen gelegten Hyphen des Achorion leicht unterscheiden lässt. 
Morphologisch von diesen ganz verschieden sind die Pilze $1,4,5$ und 6 , welche sich auch untereinander scharf differenziren.

Der Pilz 1 bildet dichte Mycelien aus sehr kurzen verfilzten Wurzelhyphen bestehend, welche nach Erschöpfung des Nährbodens oïdienartig zerfallen und ein rosenkranzähnliches Aussehen annehmen. Die peripheren geradlinig verlaufenden Fruchthyphen werden bedeutend länger, gabeln sich vielfach und doldenartig und tragen schliesslich endständige sporangienförmige Knöpfchen mit grob granulirtem, trübem Inhalt.

Pilz 4 sendet enorm lange, geradlinige Randhyphen aus, welche nur wenige Seitenäste tragen. Kügelchenbildung bäufig im Verlaufe der Hyphe, ohne deren Continuität zu unterbrechen, meist aber terminal. Die Kügelchen sind sehr klein und haben kaum den doppelten Hyphendurchmesser. Erst im geschwellten Zustande vor dem Auskeimen erreichen sie die vierfache Hyphenbreite. Eine Scheitelgabelung wie bei 1 wurde nicht beobachtet.

Pilz 5 hat wie 1 sehr kurze Mycelhyphen, unterscheidet sich von dem letzteren durch seine ebenfalls sehr kurzen Randhyphen, welche aber nur dort zur Knöpfchenbildung schreiten, wo Nahrungsmangel eingetreten ist, wie z. B. in den vegetationsfreien Zwischenräumen der büschelförmigen Protuberanzen. Wenn die Agarplatten sehr dünn gegossen sind, kann die Knöpfchenbildung auch an den Randhyphen beobachtet werden. Im Verlaufe einzelner Hyphen finden sich rundliche auf der Hyphenmembran aufsitzende Gebilde mit gelbgefärbtem, granulirtem Inhalt, welche etwa die dreifache Grösse der Köpfchen erreichen.

Pilz 6 hält, was die Länge seiner Randhyphen betrifft, ungefähr die Mitte zwischen 1 und 4. Das Hyphenende trägt ein einzelnes Köpfchen oder theilt sich gabelig in zwei oder mebrere kurze Zweige, deren Enden kolbig anschwellen und sich schliesslich zu Köpfchen gestalten. Auch jede der kurzen meist spitzwinkelig gestellten Seitenhyphen trägt ein Köpfchén. Seltener sind die im Hyphenverlauf auftretenden kugeligen Gebilde.

Bei dem Vergleiche der Quincke'schen Favuspilze mit den vorliegenden 6 Pilzen ergeben sich nur zwischen dem $\beta$-, beziehungsweise $\gamma$-Pilze Quincke's und meinem Pilze 1 beiden ge- 
meinsame morphologische und physiologische Eigenschaften. Ihr Verhalten auf Gelatine und Kartoffel, ihr Tiefenwachsthum in Agar und das Verfärbungsvermögen sind recht ähnlich. Vielleicht könnten sie durch unter congruenten Verhältnissen angestellte Culturversuche identificirt werden.

Die Varietät I des Elsenberg'schen Favuspilzes liesse sich dem Pilze 5 an die Seite stellen. Beide wachsen in ähnlicher Weise in Bouillon, Gelatine, Agar und auf Kartoffel. Die in Agarröhrchen bis an die gegenüberliegende Wand reichenden Lufthyphen und die dunkelbraune Verfärbung des Agars der Varietät II wurden bei keinem meiner sechs Fadenpilze beobachtet.

Wenn die Pilze 2 und 3 als nicht identisch angesehen werden - wozu die morphologischen und Culturdifferenzen in Bouillon, Gelatine und Agar berechtigen, - gewannen wir demnach aus den Culturen von zwei Favusfällen sechs verschiedene Hyphomyceten mit dem, den Dermophyten eigenthümlichen Typus, die bei Zimmertemperatur verzögert und mangelhaft wachsen, bei Körpertemperatur auf den verschiedensten Nährsubstraten üppig und meist auch rasch gedeihen, ohne jedoch. die Vegetationsfülle der gewöhnlichen und pathogenen Aspergillen und Mucoren auch nur annähernd erreichen zu könnén. Ich erlaube mir, zu einem Vergleiche der hier vorgelegten Reisculturen der sechs Fadenpilze mit den in meinem ausgestellten bacteriologischen Museum befindlichen Reisculturen pathogener Schimmelpilze einzuladen.

Gehen wir nun zu den bei Eczema marginatum gewonnenen Resultaten über.

Der erste Fall mit Localisation auf der inneren Oberschenkelfläche eines einundzwanzigjährigen Studenten, ergab einen exquisiten

\section{Fadenpilz 7}

der hier nur seiner Eigenschaften halber, die Gelatine nicht zu verflüssigen, bei Zimmertemperatur mangelhaft zu gedeihen und Reisscheiben etwas zu verflüssigen, hier angeführt werden möge. Seine chrom- oder goldgelben Culturen auf Kartoffel- und Reisscheiben, auf Rübenschnitten und auf Weizenbrod haben ein hübsches Aussehen. 
Der aus demselben Material rein erhaltene

Fadenpilz 8

ist der interessantere. Er verflüssigt Gelatine mit etwa der gleichen Energie wie Achorion, ohne sie zu verfärben und bildet langsam wachsende mit dichtem schneeweissen Luftmycel bedeckte flottirende Rasen mit unverfärbter Unterfläche. In Agardauerplatten erreicht der mit kurzem, dichtem, gelblichgrauem Luftmycel bedeckte Rasen in 10 bis $12 \mathrm{~d}$. einen Durchmesser von $20 \mathrm{Mm}$., wächst also selbst bei Körpertemperatur nur etwa dreimal schneller als bei gewöhnlicher. Unterfläche strohgelb oder schwefelgelblich, centraler Theil orangegelb, später roth verfärbt. $\mathrm{Zu}$ dieser Zeit beginnt der oïdienartige Zerfall der Hyphen in späterhin üppig entwickelte kugelige Gonidien, welche den Brefeld'schen Chlamydosporen entsprechen, perlenschnurartig geordnet sind und der Cultur ein zierliches Aussehen verleihen. Die nicht septirten Randhyphen bleiben vorläufig intact.

Die schmutziggelben, brombeerähnlich gewellten flachen Rasen auf Rübenschnitten haben gegenüber den wallartigen Culturen der bei Favus gefundenen. Pilze ein kümmerliches Aussehen.

Aus den Schüppchen des zweiten Falles von Eczema marginatum, ebenfalls von der Innenfläche des Oberschenkels eines fünfunddreissigjährigen Mannes entnommen, wurde der

$$
\text { Fadenpilz } 9
$$

rein erhalten.

Dieser Pilz verhält sich zu Gelatine wie der vorangehende, nur dass er noch etwas langsamer wächst und die Unterfläche des Rasens schwefelgelb verfärbt ist.

In Agarplatten entstehen grünlichgelbe, mit staubartigem Luftmycel bedeckte Rasen mit intensiv verfärbter, grünlichgelber, im Centrum bis orangegelber Unterfläche. Weder Randhyphen noch Wurzelmycel zeigen nach $14 \mathrm{~d}$. Neigung zur Gonidienbildung. Nur auf erschöpftem Nährboden involutionsartiger, unregelmässiger Hyphenzerfall.

Auf Rübenschnitten wächst der Pilz ähnlich wie 8, nur dass die Räschen etwas längeres und grauweisses Luftmycel 
tragen. Auf Reisscheiben entstehen in $8 \mathrm{~d}$. brä́unlichgelbe, auf Weizenbrod goldgelbe Rasen von $20 \mathrm{Mm}$. Durchmesser, welche mit kaum wahrnehmbarem Luftmycel bedeckt sind.

Sehen wir von dem Pilze $7 \mathrm{ab}$, so ergaben die zwei untersuchten Eczema marginatum- Fälle zwei verschiedene Pilze, welche makroskopisch ebenfalls den Dermophytentypus besitzen, aber auf den zur Anwendung gebrachten Nährböden bei Zimmer- und Körpertemperatur kümmerlicher gedeihen, als die bei Favus erhaltenen Fadenpilze.

Schliesslich möge hier noch eine kurze Beschreibung des Verfahrens der für die erwähnten Culturversuche und für mein ausgestelltes bacteriologisches Museum benützten Nährböden, der Reis- und Fleischscheiben, ihren Platz finden.

Die Bereitung des Reisbodens wird jetzt in wesentlich verschiedener, expeditiverer Weise vorgenommen, als dies zuorst im vierten Bande der "Zeitschrift für Hygiene" mitgetheilt wurde. Das fractionirte Sterilisiren des mit Milch aufgeschwemmten Reispulvers bedingt viel Zeitverlust und dann bildet sich auch durch die aufsteigenden und sich an der Oberfläche ablagernden Fettkügelchen der Milch eine Art fettreicher Kruste, welche nur eine auf die Impfstelle beschränkte und scharf begrenzte Vegetation aufkommen lässt. Der Bouillonzusatz wurde weggelassen. Bouillon verleiht fast jedem Constituens eines festen Nährbodens vorzügliche Nährkraft - kann man doch selbst mit Bouillon getränkte Gypsblöcke als Nährboden benützen. Aber wir wollen ja nicht mit allen Mitteln und auf jedem Nährboden ein üppiges Wachsthum sämmtlicher Mikroorganismen erzwingen. Uns scheint es in differentialdiagnostischer Hinsicht erwünschter, wenn wir mitunter constant negative Resultate erhalten. Aus diesem Grunde und weil Bouillon bei expeditiver Sterilisirung dem Reisboden eine gelbliche Farbe verleiht, wurde von dem Bouillonzusatze Abstand genommen.

Die erwähnten Uebelstände sind durch meine neue Methode der Reisbereitung vollständig beseitigt worden und erlaube ich mir, bezüglich der erzielten Resultate auf meine demonstrirten und ausgestellten Dauerpräparate hinzuweisen. 
$100 \mathrm{Gr}$. Reispulver werden in einer Reibschale mit $250 \mathrm{Ccm}$. abgerahmter Kuhmilch innig vermischt, in einer Porzellanschale über einer Bunsen-Flamme unter ununterbrochenem .Agitiren in einen steifen Brei überführt und letzterer noch heiss mittelst eines Hornspatels in einen sogenannten Kartoffelbohrer eingestrichen und zwar derart, dass keine $Z$ wischenräume entstehen. Nach dem Erkalten schiebt man den so erhaltenen Reiscylinder mit dem Bohrerstempel etwas hervor, schneidet mittelst eines bogenartig gefassten, straff gespannten und möglichst dünnen Platindrahtes die unebene Kuppe ab und schneidet sodann in gleicher Weise Scheiben von 6-7 Mm. Dicke, welche man sofort in die auch für Kartoffeldauerpräparate benützten Glasdosen überträgt. In jede beschickte Dose werden noch acht Tropfen Milch hinzugefügt und hierauf $1-1^{1} / 2$ Stunden im strömenden Dampfe sterilisirt.

Das Verfahren ist sehr fördernd. In einer Stunde kann man fünfzig Reisscheiben bequem fertigstellen. So bereitete Reisscheiben zeichnen sich durch vollkommene Homogenität ibrer Masse und durch ihre gleichmässige, glatte, schneeweisse Oberfläche aus. Während nach der früheren Bereitungsmethode des Reisnährbodens ausnahmslos trockene, zumeist vertiefte, auf die Impfstelle beschränkte Culturen erhalten wurden, ist das Wachsthum auf den hier beschriebenen Reisscheiben ein mannigfaltigeres. Die Spaltpilze bilden bald tropfenartige, bald weithin sich ausbreitende brei- oder salbenartige Auflagerungen, einige wenige, wie beispielsweise die Eitercoccen, auch trockene flache Krusten.

Das Herstellen des Fleischnährbodens in Scheibenform ist etwas complicirter.

Man hat vorerst das Fleisch frisch geschlachteter Thiere (Rind, Kalb, Huhn etc.) in die Form eines alkoholisirten Pulvers überzuführen. $\mathrm{Zu}$ diesem Behufe wird das sorgfältig von allem Bindegewebe befreite Fleisch in einer Fleischhackmaschine zerkleinert, der erhaltene Brei auf grossen Glasplatten in sehr dünnen Schichten ausgebreitet und bei $40-50^{\circ} \mathrm{C}$, womöglich unter Anwendung eines vorgewärmten, pilzfreien Luftstromes, getrocknet. Die erhaltene hornartige Masse lässt sich leicht zu einem feinen Pulver verreiben, welches durch das feinmaschigste Seidenflorsieb 
von gröberen Theilen und noch anhängenden Perimysien befreit wird.

Das Fleischpulver hat durch diese Manipulationen, mit Ausnahme des Wassergehaltes, nichts von den Eigenschaften des frischen rohen Fleisches eingebüsst und lässt sich in dieser Form eine unbeschränkte Zeit lang unverändert aufbewahren. Die Ausbeute an lufttrockenem Pulver beträgt aus Rindfleisch 21, aus Kalbfleisch 18 und aus Hühnerfleisch (Brustmuskeln) $20 \mathrm{Ge-}$ wichtsprocente.

Das Bereiten der Fleischscheiben verursacht weiter keine besonderen Schwierigkeiten. 100 Gr. Fleischpulver werden mit $300 \mathrm{Ccm}$. peptonisirter Fleischbrühe in einer Porzellanreibschale zu einem Brei verrieben, dieser zwischen mit Glycerin befeuchtete kreisrunde Glasplatten geschichtet, welche zu zehn bis fünfzehn übereinander - einer Volta'schen Säule ähnlich - in eine entsprechend hohe und weite Blechbüchse gebracht werden. Die Büchse, welche zweckmässigerweise mit einem Deckel mit sogenanntem Bayonnetteverschluss versehen ist, wird hierauf mit Bouillon vollgefüllt und mit dem Deckel verschlossen. Die beschickten Glasplatten sollen etwas über den Büchsenrand hervorragen, damit der Deckel sie beim Schliessen mit einigem Drucke festhält.

Die gefüllten Büchsen überlässt man 15 Minuten lang im Dampftopf einer Temperatur von $100^{\circ} \mathrm{C}$., nimmt die Glasplatten mit den nun fest gewordenen und an letzteren leicht adhärirenden Fleischscheiben vorsichtig aus den Büchsen heraus, zieht die oberste Glasplatte horizontal von der ersten Fleischscheibe ab und schneidet aus dem gelungensten Theile der letzteren mittelst des Kartoffelbohrers durch senkrechten mässigen Druck ein kreisrundes Stück heraus. Dieses wird mit einer dünnen breiten Klinge oder einem Metallspatel von der unteren Glasplatte behutsam abgelöst und in die Glasdose übertragen. So wird weiter verfahren, bis alle Fleischscheiben in eine auch technisch vollendete Form gebracht sind, worauf die gefüllten Glasdosen im strömenden Dampfe mindestens eine Stunde lang sterilisirt werden.

Die Fleischscheiben besitzen eine glatte Oberfläche und, je 
nach der Provenienz des hiezu benützten Fleisches beziehungsweise Fleischpulvers, eine lederbraune bis gelblichweisse Farbe. Auf keinem Nährboden lassen sich so eigenthümliche, charakteristische Vegetationsbilder der Hautfadenpilze erzielen, als gerade auf den Fleischscheiben. An den hier vorgeführten Culturen der sechs bei Favus gefundenen Fadenpilze sind Rasen entstanden, welche abgelöst; einem Farusscutulum täuschend ähnlich sehen.

Für bestimmte Zwecke kann man aus dem Fleischpulver auch „rohes Fleisch" als Nährboden bereiten, wenn der mit Bouillon hergestellte Fleischbrei direct in die Glasdosen eingefüllt und einer länger andauernden, fractionirten Sterilisation bei $60-62^{\circ}$ C. unterworfen wird. Hierbei muss allerdings auf Erzielung einer glatten Oberfläche des Nährbodens verzichtet werden.

Reis- und Fleischscheiben nach den erwähnten Methoden bereitet, sind ein ansserordentlich empfindliches Reagens für zufällig auffallende Luftkeime, weshalb die intacte Conservirung von Culturen auf diesen beiden Nährböden schwieriger ist, als auf allen anderen bisher verwendeten.

Bezüglich meiner ausgestellten demonstrablen Dauerpräparate in Reagensröhrchen erlaube ich mir, auf meine jüngste Mittheilung in der "Zeitschrift für Hygiene", $\mathrm{Bd}$. 5, hinzuweisen.

Wenn ich zum Schlusse nochmals kurz auf den bei Favus gefundenen Pilz 1 zurückgreife, so geschieht es, um auf eine bei diesem Pilze beobachtete eigenthümliche Wuchsform aufmerksam zu machen.

Pilz 1 bildet nämlich regelmässig auf Kartoffelscheiben und Rübenschnitten eigenartige kronen- oder gallerienartige Oesen, welche dadurch entstehen mögen, dass das periphere Wachsthum einer Falte oder eines Wulstes durch die ungehinderte Nahrungszufuhr aus dem noch nicht occupirten Substrat ein rascheres ist, als jenes des centralen Theiles und so letzterer schliesslich durch die sich senkrecht aufbanenden seitlichen Theile von seiner Basis abgehoben wird.

Eine ähnliche Erscheinung wurde auch bei einem Schizomyceten wahrgenommen: Bacillus fuscus bildet häufig auf Rüben- 
schnitten. senkrecht emporsteigende Fäden von etwa $0.2 \mathrm{Mm}$. Durchmesser, welche bei fortgesetztem Höhenwachsthum durch eigene Schwere sich wieder auf den Belag herabsenken und eine Oese mit einer Oeffnung von 0.7 bis $1.2 \mathrm{Mm}$. Durchmesser darstellen.

An der Bacillus fuscus-Cultur auf Zuckerrübe meines bacteriologischen Museums kann diese Oesenbildung, wenn der Rasen von der Seite aus betrachtet wird, leicht wahrgenommen werden.

\section{Discussion:}

Herr Pick: Geehrte Herren Collegen! Damit kein Missverständniss aufkomme in Bezug auf die Mittheilungen des Hern Král, möchte ich von vornherein bemerken, dass es sich bei seinen Untersuchungen um botanische Studien handelt, und die Frage bezüglich der Multiplicität des Favuspilzes dadurch in keiner Weise tangirt sein soll. Seine Versuche sollen vielmehr zur Vorsicht mahnen, bei den Untersuchungen an solchen pathologischen. Processen, welche von Pilzen bedingt werden, wie das also beim Favus der Fall ist, vorschnell darüber abzusprechen, ob nur ein oder mebrere Pilze als Krankheits-Erreger aufzufassen sind. Wenn Sie die Präparate des Herrn Král studiren werden, so werden Ihnen dieselben gewiss darthun, dass Herr Král eine bewunderungsw ürdige Technik und eine grosse Exactheit in der Ausführung besitzt. Er will nur das bezwecken, dass er Thnen seine Methodik u. zw. gerade am Favuspilz vorführt. In Bezug auf die pathogene Bedeutung dieser Pilze ist bisher gar nichts zu sagen. Wir haben nach dieser Richtung vorläufig noch keinerlei Versuche angestellt. Es bleibt einer späteren Zeit vorbehalten, zu entscheiden, inwiefern von diesen Pilzen irgend einer pathogen und als der eigentliche Erreger der Favuserkrankung anzusehen ist. Damit möchte ich auf den Vortrag des Herrn Collegen Jadassohn zurückkommen und bemerken, dass ich meinerseits auf demsulben Standpunkte stehe, wie vorher. Ich halte vorläufig fest daran, dass der Favus nicht von verschiedenen Pilzen hervorgerufen, dass der Favus nur von einem Pilz bedingt wird, und dass die verschiedenen, daneben gefundenen Pilze als accessorische, aber nicht als Erreger des Favus aufzufassen sind. Herr Král hat übrigens eine Reihe von Präparaten an Robert Koch nach Berlin geschickt, welche auch in der gegenwärtigen Ausstellung in Berlin, von Seiten des hygienischen Museums - mit Herrn Král's Bewilligung - ausgestellt sind.

Ich empfehle Ihnen die Besichtigung dieses ausgezeichneten Museums und ich bin fest überzeugt, dass, wenn Sie dasselbe einer eingehenden Untersuchung unterzogen haben, Sie finden werden, dass Sie hier die Resultate einer ausserordentlichen Mühewaltung und einer vorzüglich ausgebildeten Technik vor sich haben. (Lebhafter Beifall!) 
Herr Doutrelepont: Meine Herren! Ich wollte nur ein paar Worte sagen, weil ein Assistent von mir, Dr. Fabry, der jetzt schon aus der Klinik ausgetreten ist, bei mir auf der Klinik auch Favusculturen gemacht hat. Er hat die Arbeit schon an das Archiv abgeschickt und sie wird wahrscheinlich im nächsten $\mathrm{H}_{\mathrm{eft}}$ erscheinen. Auch ich will nur betonen, was auch College Pick hervorgehoben hat, dass es nämlich ausserordentlich schwer ist - da die Botaniker selbst noch nicht so weit sind - die verschiedenen uns interessirenden Pilze genau nach Arten etc. zu sondern, dass es sage ich - für uns jedenfalls um so schwerer ist, diese Fragen zu entscheiden, und ich möchte auch nicht gerade zu weit gehende Schlüsse aus den Arbeiten ziehen, die jetzt gemacht werden. Ich möchte nicht zu skeptisch sein, aber es wird noch vieler Untersuchungen über diesen Gegenstand bedürfen, ehe wir über den Favuspilz ein sicheres Urtheil gewomnen haben werden.

Herr Kaposi: Die Frage der Identität oder der differentiellen Eigenschaften der Parasiten, bei den Dermatomykosen hat seiner Zeit einen viel weiteren Umfang gehabt, damals, als sich $\mathrm{Hebra}$ auf Grund der Beobachtung des Zusammentreffens von Herpes tonsurans mit Favus die Frage aufgedrängt hat: handelt es sich hier um zwei verschiedene oder um eine und dieselbe Krankheit? - da ja bekanntlich $\mathrm{Hebra}$ unter der artificiellen Einwirkung von solchen Verhältnissen, welche für die Wucherung der Pilze günstig sind, Herpes tonsurans entstehen sah, und unter denselben Verhältnissen auch die Entwickelung von Favus beobachtete. Es ist Allen bekannt, dass seiner Zeit dieser Herpes tonsurans-Form und dem sogenannten herpetischen Vorstadium des Favus die gleiche Bedeutung beigelegt worden ist. Bei den Impfungen, die vielleicht die Herren nicht kennen, und welche der leider unlängst verstorbene Peyritsch in Innsbruck an sich selbst ausgeführt hat und von dem die Abbildungen bei uns vorliegen, war das sehr schön zu sehen.

Diese selbe Frage, die auf verschiedene Weise beantwortet worden ist, je nachdem man sie vom klinischen oder vom botanischen Standpunkte beurtheilen zu müssen geglaubt hat, ist jetzt auch wieder bezüglich der einzelnen Dermatomykosen aufgetaucht. Seiner Zeit hat Hebra, namentlich auf Grund der damals ganz und gar neuen Erfahrung von der Pleomorphie der Pilze, auf Grund deren die einzelnen Pilzformen, welche früher als verschieden angenommen worden sind, als einheitlich erkannt wurden, sich mehr für die Meinung gestimmt gefühlt, alle Dermatomykosen von einem Pilze ableiten zu sollen, und ich, einer von seinen getreuesten, vertrauensvollsten and ihn meist verehrenden Schülern - ein Wetteifer, in dem wir uns gegenseitig übertreffen wollen - habe ihm Opposition gemacht anf Grund der klinischen Erscheinungen, und ich erinnere mich nicht, dass $\mathrm{Hebra}$ das übel gedeutet hätte. Ich habe gesagt: So wie wir klinisch diese

Verh. d. D. Derm. Gesellschaft. 
Formen sich entwickeln sehen, so müssen wir sie zunächst von ver. schiedenen Species ableiten.

Nun habe ich einmal einen Botaniker von sehr gutem Namen, den die Herren alle kennen, der aber nicht wünscht, dass hier in dieser Frage sein Name genannt werde, beiläufig, inter pocula, gefragt, wie er sich gegenüber dieser Frage verhalte. Er antwortete mir: Ich verstehe nichts von dem. Das hat mir nun ungeheuer imponirt; denn er versteht viel mehr davon, als wir Alle, er hat sich aber nicht entscheiden wollen and hat gesagt: Bevor ich etwas nicht weiss, sage ich nichts.

De Bary hat sich ganz entschieden darüber ausgesprochen, und hat gesagt: „So lange die Dinge klinisch anders aussehen, haben wir Botaniker nicht das Recht zu sagen, dass diese Pilze von einer Pflanze herrühren, weil wir diese Pilze nach ihren morphologischen und Fntwickelungseigenschaften vorderhand $z \mathfrak{u}$ unterscheiden nicht im Stande sind." Folglich ist das klinische Bild massgebender. Wie meine geehrten Herren Vorredner betont haben, bin auch ich der Meinung, dass man mit den Schlussfolgerungen in dieser Richtung jetzt sehr vorsichtig sein muss, wo man die botanischen Studien in besonderer Richtung noch viel feiner ausführt, indem man Culturen der Pilze anlegt und verschiedene Formen von ihnen gezüchtet, ohne zu einem Ziele zu gelangen, dass man auf Grund verschiedener Befunde ebensowenig solche Schlussfolgerungen heutzutage machen solle, als man seiner Zeit sich sie zu machen getraute, da man nur die groben Verhältnisse studirte.

11. Herr v. Zeissl: Eine von ihm gemeinsam mit Dr. M. Horovitz ausgeführte Arbeit: „Ein Beitrag zur Anatomie der Lymphgefüsse der männlichen Geschlechtsorgane."

Die Thatsache, dass gewisse Verhältnisse der Saugadern der männlichen Geschlechtswerkzeuge nicht von allen Fachmännern in gleicher Weise dargestellt werden, war die Veranlassung, dass wir uns mit der Untersuchung der Lymphgefässe der männlichen Geschlechtstheile durch zwei Jahre beschäftigten. In den nachfolgenden Zeilen geben wir die Resultate unserer bezüglichen Untersuchungen bekannt.

Zunächst wollen wir an dieser Stelle Herrn Professor Toldt, in dessen anatomischen Institut wir unsere Arbeit ausführten, sowohl für die gütige Ueberlassung des reichlichen Materiales, als auch für die mannigfache Anregung und Unterstützung, die er uns zu Theil werden liess, unseren wärmsten Dank aussprechen. 